\title{
The adverse effects and treatment results of smoking cessation pharmacotherapy during fasting/non-fasting state
}

Running title: Smoking cessation during fasting

Iliaz S, Tural Onur S, Uysal MA, Chousein EGU, Tanriverdi E, Bagci BA, Bahadir A, Hattatoglu DG, Ortakoylu MG, Yurt S.

\begin{abstract}
:
Background: Cigarette smoking is one of the most common addictions worldwide. Muslim smokers reduce the number of cigarettes they smoke during Ramadan due to the long fasting hours.
\end{abstract}

Objectives: We aimed to share our experience in a smoking cessation clinic during Ramadan by analyzing the efficacy and adverse effects of once-daily dosing of bupropion or varenicline in a fasting group compared with conventional dosing in a non-fasting group.

Methods: We analyzed 57 patients who attended our smoking cessation clinic during Ramadan of 2014 and 2015, and at least one follow-up visit. For the fasting patients, we prescribed bupropion or varenicline after dinner (once daily) as the maintenance therapy. We recorded demographic characteristics of the patients, fasting state, drugs taken for smoking cessation, and the dosage of the medication. At the first follow-up visit, adverse effects seen with the treatment were recorded. We conducted telephone interviews 6 months after the first visits of the patients to learn the current smoking status of the groups.

Results: Of the total 57 patients, $20(35.1 \%)$ were fasting and 37 (64.9\%) were not fasting. Fasting and non-fasting patients were similar for sex, age, smoking pack-years, marital status, educational status, and mean Fagerström scores $(\mathrm{p}>0.05)$. Adverse effects and quit rates after 6 months of follow-up were similar between the fasting and non-fasting groups $(\mathrm{p}>0.05)$. 
Conclusion: Although our sample size was small, we found no difference in the rates of adverse effects or smoking cessation using a single daily oral dose of bupropion or varenicline between a fasting group and a non-fasting group that received conventional dosing.

Key words: Ramadan, fasting, single dose, smoking cessation, adverse effect, quit rate

\section{Introduction:}

Cigarette smoking is one of the most common addictions and affects almost 967 million people worldwide ( $\mathrm{Ng}$ et al, 2014). This addiction is known to decrease the life expectancy of a smoker by 10 years compared with a non-smoker (Doll, Peto, Boreham, Sutherland, 2004). Doctors and public health professionals frequently warn people to quit smoking because smoking is related with severe morbidity and mortality arising from cardiovascular diseases, cancer of many organs, and lung diseases (Dolle et al, 2004; Ezzati and Lopez, 2003). Smoking cessation counselling comprises pharmacologic treatment, and cognitive and behavioral methods. The medications used in smoking cessation are nicotine replacement therapy (NRT) (patch, gum, spray), and bupropion or varenicline tablets. These modalities have been found effective when used in appropriate patient groups. Pharmacologic treatment makes it easier for smokers to cope with abstinence from smoking (Lai, Cahill, Qin, Tang, 2010).

Religion may be a supporting factor to quit smoking. Some public health campaigns used religious beliefs for smoking cessation programs (Ghouri, Atcha, and Sheikh, 2006; Mahroof et al, 2007). The Islamic month of Ramadan is 29-30 days of religious fasting during which eating, drinking, taking medication, and smoking are prohibited during daylight hours, which ranges from 13-18 hours/day depending on the season. Smokers reduce the number of cigarettes they smoke in this month because of the limited time available for smoking. In 
smoking cessation programs, the standard method is to determine a date to quit smoking, and the patient quits smoking abruptly on that date. This method fails sometimes, and we advise quitting smoking by decreasing the number of cigarettes per day (Wennike, Danielsson, Landfeldt, Westin, Tonnesen, 2003). Oral medications used in smoking cessation are taken twice daily, but long fasting hours during Ramadan may not leave enough time to take medication twice at safe intervals. We hypothesized that giving once-daily oral smoking cessation pharmacotherapy during the Islamic month of Ramadan would provide similar smoking cessation and adverse effect profiles to twice-daily dosing. Therefore, we aimed to share our experience in a smoking cessation clinic during Ramadan by analyzing the efficacy and adverse effects of once-daily dosing of bupropion or varenicline in a fasting group compared with conventional dosing in a non-fasting group.

\section{Methods:}

In the Ramadan months of 2014 and 2015, 125 smokers presented to our smoking cessation clinic at Yedikule Chest Diseases and Thoracic Surgery Education and Research Hospital and received counselling and pharmacologic treatment to quit smoking. Out of 125 patients, only 57 patients attended the first follow-up visit to report possible adverse effects of their treatment. We analyzed the 57 patients who attended at least one follow-up visit. Treatment choices were based on nicotine dependency scores, comorbidities that could increase adverse effects, patients' choice, and doctor's preference and practice.

The Fagerström Test for Nicotine Dependence (FTND) can be used to classify patients according to the severity of their nicotine dependence. The test is composed of 6 questions; the most important questions that predict severity of dependence are the time of the first cigarette in the morning and the total number of cigarettes smoked per day. A total score of 5 points and higher means that the patient has moderate nicotine dependency and may need 
pharmacologic support to quit smoking (Heatherton, Kozlowski, Frecker, and Fagerström, 1991; Moolchan et al, 2002; Örsel et al, 2005; Payne, Smith, McCracken, McSherry, and Antony, 1994). We used that approach in our smoking cessation clinic. For the non-fasting patients, we used nicotine patches once daily, bupropion $150 \mathrm{mg}$ twice daily (the first 3 days once daily), and varenicline $1 \mathrm{mg}$ twice daily (starting with $0.5 \mathrm{mg}$ once daily for the first 3 days, then $0.5 \mathrm{mg}$ twice daily for the next 4 days, and $1 \mathrm{mg}$ twice daily thereafter as maintenance). For the fasting patients, we prescribed bupropion or varenicline once daily after dinner as the maintenance therapy instead of conventional twice daily dosing, as previously described. The reason for this dosing regimen was that 18 hours of fasting does not allow a sufficient time interval to take the second dose before the next fasting period begins. We excluded patients from the study who were taking a twice daily dose. We did not use nicotine patches in fasting patients because it does not comply with the obligations of fasting. The fasting group was informed to increase their dosage of varenicline or bupropion to twice daily after Ramadan. Smoking cessation pharmacotherapy was planned for 12 weeks with followup visits every month. We informed patients about the study and enrolled them when they gave informed written consent for the study. We recorded demographic characteristics of the patients, fasting state, drugs taken for smoking cessation, and medication dosage. At the first follow-up visit (the first visit after starting smoking cessation pharmacotherapy), adverse effects seen with the treatment were also recorded. Six months after the first visits of the patients, we conducted telephone interviews to learn the current smoking status of the groups.

Statistical Package for Social Sciences (SPSS) version 22 (Armonk, NY: IBM Corp) software was used for the statistical analysis of the data. Descriptive data are given as number of participants and frequency. Categorical variables were expressed as the number of cases and the percentage value. Comparison of categorical variables were performed using Chisquare and Fisher's exact tests. Continuous variables are given as mean and standard 
deviation. The Shapiro-Wilk test was used to determine whether the continuous variables were normally distributed. For continuous variables, Student's t-test and the Mann-Whitney U test were used according to the normality of distribution of the variables. A p value of $<0.05$ was considered statistically significant.

\section{Results:}

We enrolled 57 patients who were admitted to our Smoking Cessation Clinic during the Ramadans of 2014 and 2015. Of the total 57 patients, $20(35.1 \%)$ were fasting and 37 (64.9\%) were not fasting. Fasting and non-fasting patients were similar in terms of sex, age, smoking pack-years, marital status, educational status, and mean Fagerström scores ( $>0.05)$ (Details given in Table 1). Details of pharmacotherapy regarding fasting status are given in Table 2. The non-fasting group received their medication at the conventional dosage (twice daily for varenicline and bupropion, and once a day for nicotine patches). No patients in this group were treated with nicotine gum only. There was no statistically significant difference between the fasting and non-fasting group for the drug of choice when we excluded NRT ( $\mathrm{p}=$ $0.08)$.

When we evaluated the adverse effects of the smoking cessation drugs in the fasting and non-fasting groups, there were no statistically significant differences in the rates of depressive mood, personality change, suicidal thoughts, sweating, loss of appetite, palpitations, dyspepsia, itching, attention deficit, insomnia, mouth dryness, vivid dreams, nausea, and vomitting ( $>0.05$ ) (A detailed list of adverse effects is shown in Table 3). When we excluded the patients with NRT and only analyzed the patients with oral pharmacotherapy, the fasting/nonfasting groups remained similar for all types of adverse effects $(p>0.05)$. The most common adverse effects with smoking cessation pharmacotherapy groups were nausea $(\mathrm{n}=10)$, mouth dryness $(\mathrm{n}=24)$, attention deficit $(\mathrm{n}=10)$, and sweating $(\mathrm{n}=21)$. 
Six months after the first visit to the Smoking Cessation Clinic, we held telephone interviews and asked the current smoking status of the patients. Details of smoking cessation and fasting status of the patients are given in Table 4 . We could not reach 7 patients via phone. Of the remaining 50 patients, 17 patients (34\%) remained quit, but $33(66 \%)$ continued to smoke. Among the 17 successful quitters, 4 patients were in the fasting group. One of these 4 patients used varenicline and the remaining 3 used buproprion to quit smoking. The quitting rate did not differ according to the fasting status of the patients $(\mathrm{p}=0.19)$ or the medication used $(\mathrm{p}=0.44)$. The quit rate also did not differ according to fasting status or medication preference when NRT was excluded from the study $(\mathrm{p}=0.34$ and $\mathrm{p}=0.27$, respectively). The mean FTND scores were similar in both the fasting and non-fasting groups $(\mathrm{p}=0.17)$. We also used pharmacologic treatment for 12 patients with FTND scores <5, but only $2(16.7 \%)$ patients quit smoking.

\section{Discussion:}

Muslim religious beliefs do not support smoking. Paradoxically, smoking among Muslims is prevalent (Tobacco control country profiles, 2003). In addition, some studies reported that Muslims who were minorities in the countries in which they lived, also had higher rates of smoking (Islam and Johnson, 2005; Nierkens, Stronks, van Oel, de Vries, 2005). Nakhaee et al (Nakhaee, Divsalar, and Jadidi, 2009) concluded that religious activities may have a protective role against cigarette smoking among Muslim university students (Nakhaee et al, 2009). We aimed to evaluate the adverse effects and results of smoking cessation treatment during Ramadan. As far as we know, there are no similar studies in the literature, which makes our study unique.

The combination of pharmacologic treatment and cognitive-behavioral methods seems to be the best method of smoking cessation counselling (Lai et al, 2010). Treatment 
modalities must chosen according to the patients' demands and characteristics in order to be successful. Thus, a medicine may be useful for one patient, but not for another. Some patients may not believe in patches and think that these are not effective. We prefer oral medication in that group. If a patient does not want to use pills, we can prescribe NRT or use cognitive/behavioral methods alone. Smoking cessation rates are low in smoking cessation clinics, despite the number of smokers who are admitted. Therefore, we have to respect the needs and beliefs of smokers in order to be successful in smoking cessation counselling.

In our smoking cessation clinic, we primarily use the FTND score to determine whether a pharmacological agent should be prescribed (Uysal et al, 2004). We prefer giving medication as oral or NRT for FTND scores of 5 and higher. However, this is not the sole criteria for pharmocotherapy. The FTND score does not predict the success of a pharmacotherapy. In the present study, the mean FTND scores were above 5 in both the fasting and non-fasting groups. We also used pharmacologic treatment for 12 patients with an FTND score $<5$, but only 2 patients quit smoking successfully. These data show that it could be hard to quit even for mild smokers, and there might be multiple factors that determine the success of quitting.

There are data on the single oral dose administration of varenicline in the literature (Faessel et al, 2006). With the exception of nausea, there was no increase in adverse effects even with high doses of varenicline up to $10 \mathrm{mg}$. With doses higher than $3.0 \mathrm{mg}$, immediate vomitting occurred and the study concluded that nausea limited using higher doses of varenicline. When varenicline was administered after a meal, tolerability associated with nausea was greater compared with fasting. Food did not affect oral bioavailability of varenicline. According to that study, plasma varenicline concentrations after a single oral dose declined from 10.1 hours to 25.6 hours (Faessel et al, 2006). In our study, our patients took varenicline as a single oral dose of $1 \mathrm{mg}$ after a meal. In our comparison of the fasting group 
with the non-fasting group, which took $1 \mathrm{mg}$ twice daily, we found no differences in the rate of adverse effects. Smoking cessation rates were also similar. One month of different dosing during Ramadan may not have changed or affected the overall smoking cessation rate because we reverted to twice daily varenicline and bupropion after Ramadan. Also the duration of low dosing was different for some patients, as determined by the date of the first attendance to the outpatient clinic. This is a limitation of our study.

Another limitation of our study is that the adverse effects and smoking status after 6 months were evaluated according to the patients' statements. We do not know whether the patients had really quit because we did not perform any biochemical analyses for confirmation. Another limitation is small sample group of our study. The cause for this was the low follow-up visit attendance rate at the smoking cessation clinic. Furthermore, we gave once-daily bupropion or varenicline to the fasting group because of the long hours of fasting. The two groups did not receive the same dosage of medicine, and this inequality may be a limitation to evaluate adverse effects of smoking cessation pharmocotherapy.

In conclusion, this is the first study in the literature to evaluate Muslim patients admitted to smoking cessation clinics during Ramadan. Although our sample size was small, we found no differences in the rates of adverse effects or smoking cessation between the fasting group, which used a single oral dose of bupropion or varenicline, and the non-fasting convetionally-treated group. Studies with larger sample sizes are needed to draw firm conclusions in this issue.

\section{Declaration of interest:}

There are no conflicts of interest to declare.

\section{Acknowledgement:}


Our thanks to Mr. David F. Chapman for English language editing.

\section{References:}

Doll R, Peto R, Boreham J, Sutherland I. (2004). Mortality in relation to smoking: 50 years' observations on male British doctors. BMJ,328(7455):1519.

Ezzati M, Lopez AD. (2003). Estimates of global mortality attributable to smoking in 2000. Lancet,362:847-852.

Faessel HM, Smith BJ, Gibbs MA, Gobey JS, Clark DJ, Burstein AH. (2006). Single-dose pharmacokinetics of varenicline, a selective nicotinic receptor partial agonist, in healthy smokers and nonsmokers. J Clin Pharmacol,46(9):991-998.

Ghouri N, Atcha M, Sheikh A. (2006). Influence of Islam on smoking among Muslims. BMJ, 332: 291-294.

Heatherton TF, Kozlowski LT, Frecker RC, Fagerström KO. (1991). The Fagerström Test for Nicotine Dependence: a revision of the Fagerström Tolerance Questionnaire. Br J Addict, 86:1119-1127.

Islam SMS, Johnson CA. (2005). Influence of known psychosocial smoking risk factors on Egyptian adolescents' cigarette smoking behaviour. Health Promot Int,20:135-145.

Lai DT, Cahill K, Qin Y, Tang JL. (2010). Motivational interviewing for smoking cessation, Cochrane Database Syst Rev, 1:CD006936.

Mahroof R, Syed R, El-Sharkawy A, Hasan T, Ahmed S, Hussain F. (2007). Ramadan Health Guide. London: The Stationery Office; p. 1-30.

Moolchan ET, Radzius A, Epstein Dh, Uhl G, Gorelick DA, Cadet JL, Henningfield JE. (2002). Fagerström test for nicotine dependence and the diagnostic interview schedules: Do they diagnose the same smokers? Addict Behav, 27: 101-103. 
Nakhaee N, Divsalar K, Jadidi N. (2009). Religious involvement and cigarette smoking among Iranian university students. Int J Psychiatry Med, 39(2) 189-198.

Ng M, Freeman MK, Fleming TD, Robinson M, Dwyer-Lindgren L, Thomson B, Wollum A, Sanman E, Wulf S, Lopez AD, Murray CJL, Gakidou E. (2014). Smoking Prevalence and Cigarette Consumption in 187 Countries, 1980-2012. JAMA,311(2):183-192.

Nierkens V, Stronks K, van Oel CJ, de Vries H. (2005). Beliefs of Turkish and Moroccan immigrants in The Netherlands about smoking cessation: Implications for prevention. Health Educ Res, 20:622-34.

Örsel O, Örsel S, Alpar S, Uçar N, Güven SF, Şipit T, Kurt B. (2005). Sigara birakmada nikotin bağımlılık düzeylerinin tedavi sonuçlarına etkisi. Solunum Hastalıkları, 16: 112-118. Payne JP, Smith PO, McCracken LM, McSherry WC, Antony MM. (1994). Assessing nicotine dependence: a comparison of the Fagerström tolerence questionnaire (FTQ) with the Fagerström test for nicotine dependence (FTND) in a clinical sample. Addict Behav, 19: 307317.

Tobacco control country profiles. (2003). The 12th world conference on tobacco or health. In Helsinki, Finland. Second editon 2003. Available from: http://www.who.int/tobacco/global_data/country_profiles/Introduction.pdf (accessed date April 2015).

Uysal MA, Kadakal F, Karşidağ C, Bayram NG, Uysal O, Yilmaz V. (2004). Fagerstrom test for nicotine dependence: reliability in a Turkish sample and factor analysis. Tuberk Toraks,52(2):115-21.

Wennike P, Danielsson T, Landfeldt B, Westin A, Tonnesen P. (2003). Smoking reduction promotes smokingcessation: results from a double blind, randomized, placebo-controlled trial of nicotine gum with 2-year follow-up. Addiction, 98:1395-1402. 
Table legends:

Table 1: Demographic characteristics of the patients

Table 2: The distribution of drug of choice for smoking cessation according to fasting and non-fasting groups

Table 3: Detailed list of adverse effects and their frequency according to fasting state

Table 4: Distribution of the patients according to smoking cessation and fasting state.

\begin{tabular}{|l|l|l|l|}
\hline \multicolumn{2}{|l|}{ Table 1: Demographic characteristics of the patients } \\
\hline & Fasting, n (\%) & Non-fasting, n (\%) & P value \\
\hline Gender (male) & $11(55 \%)$ & n=37 & \\
\hline Age, mean \pm SD (years) & & & \\
\hline Marrital status (married) & $47 \pm 12$ & $47 \pm 12$ & 0.79 \\
\hline Smoking pack-years, mean \pm SD & $39.9 \pm 29.6$ & $39.6 \pm 26$ & 0.95 \\
\hline Educational Status (graduated & $6(30 \%)$ & $11(29.7 \%)$ & 0.75 \\
\hline from high school or higher) & & & \\
\hline Fagerström score, mean \pm SD & $5.65 \pm 2.48$ & $6.57 \pm 2.29$ & 0.98 \\
\hline SD: standard deviation & & & \\
\hline
\end{tabular}




\begin{tabular}{|l|l|l|}
\hline \multicolumn{2}{|l|}{ Table 2: The distribution of drug of choice for smoking cessation according to fasting } \\
and non-fasting groups & Non-fasting, n (\%) \\
\hline Type of smoking cessation & Fasting, n (\%) & $\mathbf{n = 3 7}$ \\
\hline medication & $\mathbf{n = 2 0}$ & $0(0 \%)$ \\
\hline Transdermal nicotine patch & $0(0 \%)$ & $10(27 \%)$ \\
\hline Bupropion* & $1(5 \%)$ & $10(27 \%)$ \\
\hline Varenicline* & $12(60 \%)$ & $17(45.9 \%)$ \\
\hline For the fasting group, this medication was prescribed once daily and after the dinner. \\
\end{tabular}

\begin{tabular}{|l|l|l|l|}
\hline \multicolumn{2}{|l|}{ Table 3: Detailed list of adverse effects and their frequency according to fasting state } \\
\hline Adverse effects & Fasting, n (\%) & Non-fasting, n (\%) & P value \\
& n=20 & n=37 & \\
\hline Nausea & $3(15 \%)$ & $7(18.9 \%)$ & $>0.99$ \\
\hline Vomitting & $0(0 \%)$ & $3(8.1 \%)$ & 0.55 \\
\hline Vivid dreams & $2(10 \%)$ & & $>0.99$ \\
\hline Mouth dryness & $10(50 \%)$ & $14(37.8 \%)$ & 0.38 \\
\hline Insomnia & & & 0.64 \\
\hline
\end{tabular}




\begin{tabular}{|l|l|l|l|}
\hline Attention deficit & $4(20 \%)$ & $6(16.2 \%)$ & 0.73 \\
\hline Itching & $3(15 \%)$ & $4(10.8 \%)$ & 0.69 \\
\hline Dyspepsia & $3(15 \%)$ & $5(13.5 \%)$ & $>0.99$ \\
\hline Palpitation & $1(5 \%)$ & $6(16.2 \%)$ & 0.40 \\
\hline Loss of appetite & $2(10 \%)$ & $4(10.8 \%)$ & $>0.99$ \\
\hline Sweating & & $16(43.2 \%)$ & 0.17 \\
\hline Thought of suicide & $0(0 \%)$ & $1(2.7 \%)$ & $>0.99$ \\
\hline Personality change & $4(20 \%)$ & $4(10.8 \%)$ & 0.43 \\
\hline Depressive mood & $0(0 \%)$ & $4(10.8 \%)$ & 0.29 \\
\hline
\end{tabular}

Table 4: Distribution of the patients according to smoking cessation and fasting state.

\begin{tabular}{|r|l|l|}
\hline & $\begin{array}{l}\text { Fasting, n (\%) } \\
\mathbf{n = 2 0}\end{array}$ & $\begin{array}{l}\text { Non-fasting, n (\%) } \\
\mathbf{n}=\mathbf{3 7}\end{array}$ \\
\hline Quitters & $4(20 \%)$ & $13(35.1 \%)$ \\
Bupropicline & 1 & 5 \\
NRT & 3 & 4 \\
\hline Active smokers & 0 & 4 \\
Varenicline & 6 & $19(51.4 \%)$ \\
Bupropion & 7 & 12 \\
NRT & 1 & 3 \\
\hline
\end{tabular}


